\title{
Metal Particulate Matter Components Affect Gene Expression and Beat Frequency of Neonatal Rat Ventricular Myocytes
}

\author{
Donald W. Graff, ${ }^{1}$ Wayne E. Cascio, ${ }^{2,3}$ Joseph A. Brackhan, ${ }^{2}$ and Robert B. Devlin ${ }^{1}$
}

${ }^{1}$ National Health and Environmental Effects Research Laboratory, U.S. Environmental Protection Agency, Research Triangle Park, North Carolina, USA; ${ }^{2}$ Division of Cardiology, Department of Medicine, and ${ }^{3}$ Asthma and Lung Biology, The Center for Environmental Medicine, University of North Carolina, Chapel Hill, North Carolina, USA

Soluble particulate matter (PM) components (e.g., metals) have the potential to be absorbed into the bloodstream and transported to the heart where they might induce the expression of inflammatory cytokines and remodel electrical properties. We exposed cultured rat ventricular myocytes to similar concentrations of two metals [zinc $(\mathrm{Zn})$ and vanadium $(\mathrm{V})$ ] found commonly in PM and measured changes in spontaneous beat rate. We found statistically significant reductions in spontaneous beat rate after both short-term (4-hr) and long-term (24-hr) exposures, with a more substantial effect seen with $\mathrm{Zn}$. We also measured the expression of genes associated with inflammation and a number of sarcolemmal proteins associated with electrical impulse conduction. Exposure to $\mathrm{Zn}$ or $\mathrm{V}(6.25-50 \mu \mathrm{M})$ for $6 \mathrm{hr}$ produced significant increases in IL-6, IL-1 $\alpha$, heat shock protein 70, and connexin 43 (Cx43). After $24 \mathrm{hr}$ exposure, $\mathrm{Zn}$ induced significant changes in the gene expression of Kv4.2 and KvLQt (potassium channel proteins), the $\alpha_{1}$ subunit of the L-type calcium channel, and Cx43, as well as IL- 6 and IL-1 $\alpha$. In contrast, V produced a greater effect on $\mathrm{Cx} 43$ and affected only one ion channel (KvLQT1). These results show that exposure of rat cardiac myocytes to noncytotoxic concentrations of $\mathrm{Zn}$ and $\mathrm{V}$ alter spontaneous beat rate as well as the expression of ion channels and sarcolemmal proteins relevant to electrical remodeling and slowing of spontaneous beat rate, with $\mathrm{Zn}$ producing a more profound effect. As such, these data suggest that the cardiac effects of PM are largely determined by the relative metal composition of particles. Key words: beat frequency, cardiac myocytes, cytokines, gap junctions, ion channels, metals, particulate matter. Environ Health Perspect 112:792-798 (2004).

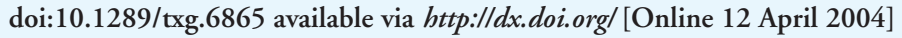

Epidemiologic evidence links exposure to ambient air pollution particulate matter (PM) to morbidity and mortality associated with adverse cardiovascular health outcomes, including discharges of internal cardiac defibrillators and hospitalizations and death due to arrhythmia and myocardial infarction [Peters et al. 2000, 2001; U.S. Environmental Protection Agency (U.S. EPA) 1996]. Exposure to PM may account for as many as 60,000 cardiopulmonary deaths each year in the United States [National Resource Defense Council (NRDC) 1996; U.S. EPA 1996]. Reports of changes in heart rate and heart rate variability suggest that altered cardiac electrophysiological processes play a role in PM-induced morbidity and mortality (Liao et al. 1999; NRDC 1996; Peters et al. 2000). Additionally, several studies have reported correlations between PM exposure and cardiovascular inflammatory responses, which could lead to ischemic events (Pekkanen et al. 2002; Peters et al. 2001; Ross 1999), or alternatively, could induce electrical remodeling of the myocardium. It has been proposed that PM exerts its cardiac effects indirectly through modulation of autonomic control of the heart (Pope et al. 1999). An alternative hypothesis is that the production of inflammatory mediators produced at sites distant from the heart (e.g., the lungs or blood vessels) are transported to the heart, where they produce cardiac pathology (Frampton 2001). However, it has also been suggested that particle components may reach the systemic circulation (Nemmar et al. 2002) and can reach the heart (CalderonGarciduenas et al. 2001), where they may produce direct effects on cardiac myocytes, resulting in inflammation, arrhythmia, or myocardial infarction. Nevertheless, a definitive mechanism, particle, or particle component responsible for the increase in cardiovascular morbidity and mortality has yet to be identified.

PM is a complex mixture containing many different components including metallic compounds such as iron, zinc ( $\mathrm{Zn})$, copper, vanadium (V), and nickel. Such metals are particularly potent inducers of physiological effects in both animals and humans. Two of these metals, $\mathrm{Zn}$ and $\mathrm{V}$, are found in PM samples from a number of sources and their water solubility in various chemical forms suggests the potential for systemic absorption after inhalation. Previous studies have reported that $\mathrm{Zn}$ and $\mathrm{V}$ can produce physiological changes in cardiac myocytes (Campen et al. 2002; Evangelou and Kalfakakou 1993; Kodavanti et al. 2003; Werdan et al. 1980). However, to our knowledge, a direct comparison of these two metals in the same in vitro experimental system has not been reported previously.
$\mathrm{Zn}$ and $\mathrm{V}$ may well produce changes in cardiac function by altering the normal gene expression of membrane proteins that contribute to electrical signal propagation or through the stimulation of inflammation mediators that exert direct effects on cardiac myocytes. A complex system of ion channels and biochemical transport mechanisms function in concert to initiate and regulate the heartbeat and subsequent impulse propagation throughout the heart. It is well known that disease states such as hypertension and ischemic heart disease promote systemic and local inflammatory processes, resulting in interstitial inflammation and myocyte hypertrophy. These processes alter the normal cardiac structure and function and induce changes in the expression of voltage-gated channels controlling inward and outward membrane currents and intercellular currents. Changes in gene expression and subsequent effects on membrane proteins and currents and their cumulative effects on tissue electrical properties are known as electrical remodeling and contribute to arrhythmogenesis.

In this study we observed that $\mathrm{Zn}$ and $\mathrm{V}$ produce important contrasting effects on myocyte function and gene expression of several cardiac proteins at equimolar concentrations. We report that $\mathrm{Zn}$ exposure produces a greater decrease in spontaneous beat rate, a sensitive biosensor capable of detecting physiologically relevant changes in active and passive membrane properties

Address correspondence to D. Graff, National Health and Environmental Effects Research Laboratory, U.S. EPA, MD 58D, Research Triangle Park, NC 27711 USA. Telephone: (919) 843-5155. Fax: (919) 966-6271. E-mail: graff.don@epa.gov

We acknowledge L. Dailey and R. Silbajoris for their work on the RT-PCR experiments, and K. Dreher and J. Samet for their careful review of this manuscript.

The information described in this article has been reviewed by the National Health and Environmental Effects Research Laboratory, U.S. Environmental Protection Agency, and has been approved for publication. Approval does not signify that the contents necessarily reflect the views and policy of the agency, nor does mention of trade names or commercial products constitute endorsement or recommendation of use.

The authors declare they have no competing financial interests.

Received 17 November 2003; accepted 7 April 2004 . 
and a surrogate for heart rate. We also note that $\mathrm{Zn}$ produces a more profound effect on the accumulation of mRNAs coding for several potassium channels, a cardiac calcium channel, and a gap junction protein, indicating that $\mathrm{Zn}$ may precipitate an electrical remodeling process in the heart. Our data suggest that $\mathrm{Zn}$ and $\mathrm{V}$ can affect the function of cardiac myocytes and thus provide biological plausibility to previous epidemiologic studies linking PM exposure to negative cardiovascular health outcomes. Furthermore, our cell culture model demonstrates that PM rich in $\mathrm{Zn}$ may produce a greater direct effect on the heart than PM equally rich in $\mathrm{V}$.

\section{Materials and Methods}

\section{Cell Culture}

Rat ventricular myocytes were isolated from 1-day-old Sprague-Dawley rats (CRL:CD; Charles River, Wilmington, MA) in compliance with guidelines established by the National Institutes of Health (NIH 1996) and with the approval of the Institutional Animal Care and Use Committee at the University of North Carolina at Chapel Hill. After trypsin and collagenase digestions, the cells were resuspended in medium 199 supplemented with $10 \%$ fetal calf serum (FCS) and penicillin/streptomycin $(20 \mathrm{U} / \mathrm{mL}$ and $0.02 \mathrm{mg} / \mathrm{mL}$, respectively) and fibroblasts were removed by preplating in $750-\mathrm{mL}$ cell culture flasks. The flasks were then rinsed, and the resulting myocyte suspensions were diluted with medium 199 supplemented with $10 \%$ FCS, penicillin/streptomycin (20 U/0.02 mg/mL) and bromodeoxyuridine $(5 \mu \mathrm{g} / \mathrm{mL})$ and plated in laminin-coated plastic dishes at a density of approximately 250,000 cells $/ \mathrm{cm}^{2}$. Basic media and serum conditions were constant during all experiments to avoid a potential stress response and cell death due to serum depletion (Leicht et al. 2001). All cultures were maintained at $37^{\circ} \mathrm{C}$ under an atmosphere containing $5 \% \mathrm{CO}_{2}$. Experiments were conducted using 11- to 13-day-old confluent monolayers of spontaneously beating myocytes. The sulfate salts of each metal were used in the exposure experiments.

\section{Toxicity Experiments}

Cytotoxicity produced by varying concentrations of $\mathrm{Zn}$ and $\mathrm{V}$ were assessed using the CytoTox 96 nonradioactive cytotoxicity assay (Promega, Madison, WI). Briefly, lactate dehydrogenase (LDH) enzyme in culture supernatants was measured with a 30 -min coupled enzymatic assay that results in the conversion of a tetrazolium salt into a red formazan product, with the amount of color formed being proportional to the number of lysed cells. Cardiac ventricular myocytes were grown in sixwell plates under the conditions described above for 11 days. Aliquots of the supernatants were collected after $24 \mathrm{hr}$ in control media and immediately assayed for baseline LDH release under nonstimulated conditions. The media was then removed and replaced with media containing 0 , $6.25,12.5,25$, or $50 \mu \mathrm{M} Z n$ or V. After 24-hr exposure, aliquots of the supernatants were assayed for LDH. The media was removed and replaced with media containing $1 \%$ Triton $\mathrm{X}-100$ for $30 \mathrm{~min}$ to lyse the cells, thereby providing a measure of maximal LDH release. Aliquots were again obtained and assayed for LDH. To compute percent cytotoxicity, we divided the experimental and control absorbance values by the corresponding maximal absorbance values.

\section{Beat Rate Experiments}

Measurements of spontaneous beat rate were conducted on cells grown in plastic $35-\mathrm{mm}$ cell culture dishes in the conditions described above. Baseline beat rate measurements (beats per min) were obtained using a Nikon DIC inverted microscope (Nikon Instruments Inc., Melville, NY) connected to a Hitachi CCD camera (Hitachi Denshi, Ltd., Woodbury, NY). Images were displayed on a Sony video monitor (Sony Corp., New York, NY) and simultaneously recorded with a JVC VHS video recorder (JVC Professional Products, Wayne, NJ). Freshly prepared $\mathrm{Zn}$ or $\mathrm{V}$ sulfate stock solution was then added to the medium to reach the desired final concentration $(0$, $6.25,12.5,25$, or $50 \mu \mathrm{M})$, and the effect on beat rate was measured at $0.5,1,2,4$, and $24 \mathrm{hr}$. Three measurements were taken from each culture dish, which was marked with a pen in three randomly chosen spots to ensure that repeat measurements were taken from the same groups of cells. Temperature was constantly maintained at $37^{\circ} \mathrm{C}$ using an infrared heating lamp in an incubation chamber surrounding the microscope stage.

\section{Reverse Transcription and Real-Time Polymerase Chain Reaction}

Cells were grown in 24-well plates as described previously and exposed to control media or media containing $\mathrm{Zn}$ or $\mathrm{V}$ $(6.25,12.5,25$, or $50 \mu \mathrm{M})$ for 6 or $24 \mathrm{hr}$. Extraction of RNA, first-strand cDNA synthesis, and DNA amplification were performed by methods described previously with minor modifications (Carter et al. 1997). Cells were lysed in buffered guanidine isothiocyanate $(6 \mathrm{M})$ and sheared through a 25-gauge needle. RNA was pelleted by ultracentrifugation onto a 5.7 M cesium chloride cushion for $2 \mathrm{hr}$, resuspended in Tris-EDTA buffer, and precipitated overnight at $-80^{\circ} \mathrm{C}$ in $70 \%$ ethanol and $0.15 \mathrm{M} \mathrm{NaCl}$. RNA concentrations were determined using the Ribogreen assay (Molecular Probes, Inc., Eugene, OR). cDNA was synthesized from 100 to 200 ng RNA using a reverse transcriptase (RT) reaction in a total volume of $100 \mu \mathrm{L}$ with $10 \times$ polymerase chain reaction (PCR) buffer, a dNTP mix, random hexamers, Rnasin, and marine leukemia virus $\mathrm{RT}$.

Quantitative real-time PCR was performed using TaqMan polymerase with detection of FAM (6-carboxy-fluorescein) fluorescence on a sequence detector (ABI PRISM 7700; PerkinElmer Applied Biosystems, Foster City, CA). Rat oligonucleotide primer pair sequences (Integrated DNA Technologies, Inc., Coralville, IA) for each gene of interest are listed in Table 1. Serial dilutions of cDNA isolated from unexposed rat ventricular myocyte cultures were analyzed and used for standard curves. Mouse glyceraldehyde-3-phosphate dehydrogenase sequence served as an internal control. cDNA samples were subjected to 40 cycles on the sequence detector, and the threshold was set at a point consistent among the samples and on the linear upslope. Only the resulting curves with a correlation coefficient above 0.98 were used to assure the accuracy of the data.

\section{Statistics}

Statistical analyses were performed using GraphPad Prism software, version 3.02 (GraphPad Software, Inc., San Diego, CA). The 0 - to 4-hr beat rate experiments used a repeated measures analysis of variance (ANOVA), whereas 0- to 24-hr beat rate measurements (performed in separate experiments) were compared using a paired $t$ test. Standard ANOVA was used for LDH and mRNA data comparisons. Dunnett's test was used after ANOVA for post hoc analysis to determine the treatment groups that differed from baseline or control where appropriate. Values are expressed as means \pm SEM. Differences were considered statistically significant at $p<0.05$.

\section{Results}

To determine whether $\mathrm{Zn}$ or $\mathrm{V}$ affect the physiologic function of cardiac myocytes in culture, we exposed cells to 6.25 - to $50-\mu \mathrm{M}$ concentrations of each metal, then measured the spontaneous beat rate of the myocytes at various times after exposure. These concentrations were chosen partly 
because they did not induce significant cellular injury as determined by release of $\mathrm{LDH}$ (Figure 1). The effects of $\mathrm{Zn}$ exposure on the spontaneous beat rate of myocytes are shown in Figure 2A. A 30 -min exposure to $50 \mu \mathrm{M} \mathrm{Zn}$ sulfate produced a significant decrease in spontaneous beat rate compared with baseline, an effect that persisted for $24 \mathrm{hr}$. Lower concentrations of $\mathrm{Zn}$ also caused a decrease in spontaneous beat rate, although longer exposure times were required. Figure $2 \mathrm{~B}$ shows that $\mathrm{V}$ exposure also resulted in a decrease in spontaneous myocyte beat rate, albeit to a lesser extent than $\mathrm{Zn}$.

The rate of spontaneous beating of cardiac cells in culture is determined by a number of factors, including the rate of spontaneous depolarization of latent pacemaker cells and the passive resistive properties of the cellular syncitium. These factors are directly influenced by changes in voltage-gated channels and structural proteins such as gap junctions. Therefore, in subsequent experiments we exposed cardiac myocytes to concentrations of $\mathrm{Zn}$ and $\mathrm{V}$ similar to those used in the beat rate experiments to determine whether these metals also produce dissimilar effects on ion channel, gap junction protein, and inflammatory mediator mRNA accumulation. Exposure of cells for $6 \mathrm{hr}$ to $\mathrm{Zn}$ resulted in significant changes in gene expression of two inflammatory cytokines (IL-6, IL-1 $\alpha$ ) as well as heat shock protein (HSP)70 (Figure 3A). Zn exposure also increased connexin $43(\mathrm{Cx} 43)$ gene transcripts by approximately $50 \%$ but otherwise did not affect the mRNA accumulation of genes encoding $\mathrm{Cx} 40$ or other ion channels studied (Figure 3B). Exposure of cells to $\mathrm{V}$ for $6 \mathrm{hr}$ also resulted in increased levels of mRNAs coding for IL- 6 , IL- $1 \alpha$, and HSP70 (Figure 4A) but not $\mathrm{Cx} 43$ (Figure 4B).

Exposure of cells to $\mathrm{Zn}$ and V for $24 \mathrm{hr}$ yielded results quite different from those seen at $6 \mathrm{hr}$. As shown in Figure 5A, cells exposed to $\mathrm{Zn}$ had an even greater increase in accumulation of mRNAs coding for
IL-6 and HSP70 than seen after 6-hr exposure, although IL-1 $\alpha$ gene expression was no longer significantly altered (Figure 5A). However, marked changes in gene expression of several ion channel and gap junction proteins were also observed (Figure 5B). Zn exposure resulted in statistically significant dose-dependent increases in three of the four potassium channels studied (Kv1, Kv4.2, KvLQT1), the $\alpha_{1}$ subunit of the L-type calcium channel, and Cx43. Exposure of cells to $\mathrm{V}$ for $24 \mathrm{hr}$ resulted in a significant dose-dependent increase in IL- 6 and IL- $1 \alpha$ gene expression but not HSP70 expression (Figure 6A). $\mathrm{Cx} 43$ gene expression was also increased at $24 \mathrm{hr}$, but in marked contrast to $\mathrm{Zn}, \mathrm{V}$ exposure did not cause an increase in ion channel gene expression (Figure 6B). One ion channel (KvLQT1) actually had significantly decreased mRNA accumulation.

\section{Discussion}

The results of this study indicate that the soluble metal composition of PM may be particularly important when one is assessing cardiac toxicity associated with PM exposure. Both $\mathrm{Zn}$ and $\mathrm{V}$ modulate the function of cardiac myocytes by slowing their spontaneous beat rate, analogous to slowing of heart rate previously demonstrated in rats instilled with residual oil fly ash containing high amounts these metals (Campen et al. 2002; Wichers et al. 2004). However, compared with $\mathrm{V}$, the decrease induced by $\mathrm{Zn}$ was significantly more pronounced and occurred at lower concentrations with shorter exposure times. The distinct responses to these two metals is not surprising, as earlier work has shown that $\mathrm{Zn}$ and $\mathrm{V}$ produce dissimilar effects in guinea pig heart contractile rate (Evangelou and Kalfakakou 1993; Kalfakakou et al. 1993) and rat myocyte beat rate (Werdan et al. 1980).

Numerous transcriptional and posttranslational modifications may account for the changes in spontaneous beat rate that we observed. Rapid changes (those occurring within $4 \mathrm{hr}$ ) likely result from direct effects of the ions themselves on the channels or from posttranslational protein modifications. Although this study does not address this type of posttranslational effect, we are currently conducting experiments exploring the effects of $\mathrm{Zn}$ and $\mathrm{V}$ on protein phosphorylation to gain mechanistic insight into the rapid effects these ions have on spontaneous beat rate. In an effort to investigate potential molecular mechanisms requiring transcriptional changes that may not be evident within $4 \mathrm{hr}$ of exposure, we chose to study alterations in gene expression after longer exposures to $\mathrm{Zn}$ and $\mathrm{V}$ ( 6 and $24 \mathrm{hr}$ ),

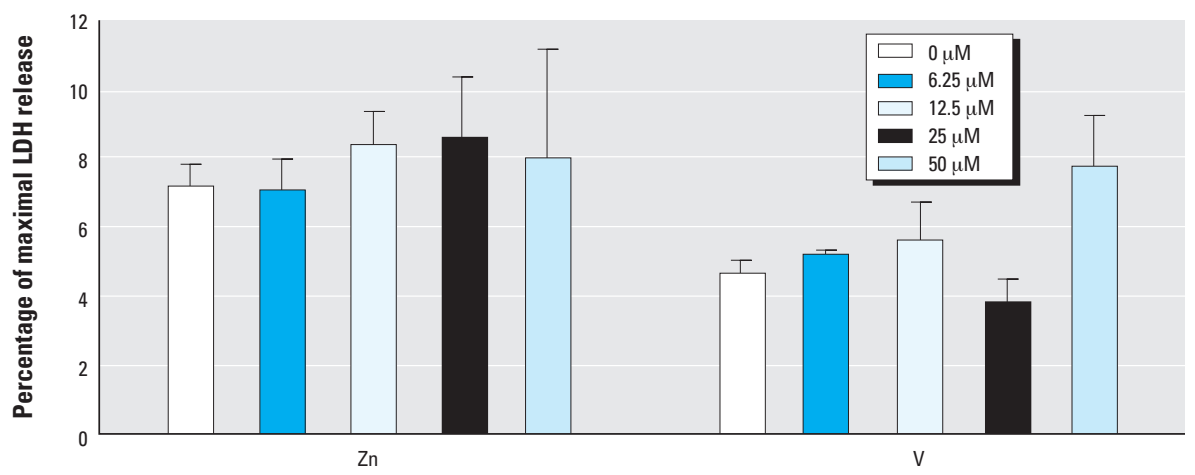

Figure 1. LDH release after stimulation with $0,6.25,12.5,25,50 \mu \mathrm{M} \mathrm{Zn}$ or $\mathrm{V}$ for $24 \mathrm{hr}$. Data from four experiments are expressed as a mean $( \pm$ SEM) percentage of the maximal LDH release stimulated by $1 \%$ Triton X-100 treatment. Using ANOVA, no difference from control was found at any concentration of either metal.

Table 1. PCR oligonucleotide primer sequences.

\begin{tabular}{|c|c|c|c|}
\hline Gene & Accession no. ${ }^{a}$ & Sense & Antisense \\
\hline $\mathrm{Cx40}$ & AF021806 & 5'-CCAAAATGTCTGCTACGACCAA-3' & 5'-GGACACAAAGATGATCTGCAGTA-3' \\
\hline Cx43 & NM_012567 & 5'-GCCCAGCCGTTCGATTT-3' & 5'-AGTTCATGTCCAGCAGCAACTTT-3' \\
\hline Kv1 & M27158 & 5'-GCAGCGTCTCTGGAGCACTT-3’ & 5'-ATGGATCGGCCAGTGTCCTA-3’' \\
\hline Kv4.2 & NM_031730 & 5'-TCGTGTCTAACTTCAGTCGGATCT-3' & 5'-GGCCAGCCTCGCTTTCTT-3' \\
\hline KvLOT1 & U926-55 & 5'-GGGTATCCGCTTCCTTCAAAT-3' & 5'-CCAGGAGCCTCCAGGTACCT-3' \\
\hline L-type $\mathrm{Ca}^{2+}$ channel ( $\alpha_{1}$ subunit) & S74397 & 5'-TGACATCGAGGGTGAAAACTGT-3' & 5'-GGCTGAACTTGGATTTGGAGAT-3' \\
\hline IL-6 & NM_012589 & 5'-ATATGTTCTCAGGGAGATCTTGGAA-3' & 5'-GTGCATCATCGCTGTTCATACA-3' \\
\hline$\| \mathrm{L}-1 \alpha$ & NM_017019 & 5'-AGGGCACAGAGGGAGTCAACt-3' & 5'-AAGTCAGGAACTTTGGCCATCTT-3' \\
\hline HSP70 & NM_031971 & 5'-AAGATCAGCGAGGCTGACAAG-3' & 5'-TCTTTCTCAGCCAGCGTGTTAG-3' \\
\hline GAPDH & NM_008084 & 5' -CATGGCCTTCCGTGTTCCTA-3' & 5'-TGTCATCATACTTGGCAGGTTTCT-3' \\
\hline
\end{tabular}

${ }^{a} A c c e s s i o n$ numbers are from GenBank (http://www.ncbi.nlm.nih.gov/entrez/query.fcgi?db=Nucleotide). 

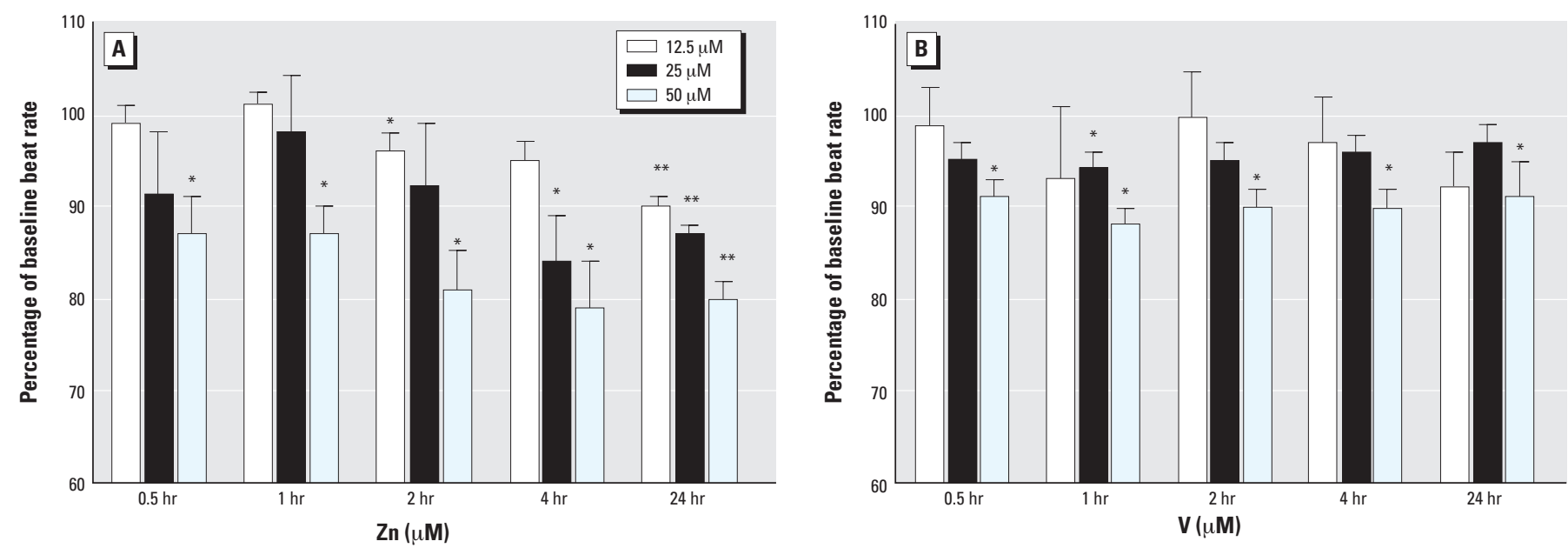

Figure 2. Zn- and V-induced changes in the spontaneous beat rate of myocytes in culture after exposure to $12.5,25$, or $50 \mu \mathrm{M} Z \mathrm{n}(A)$ or $\mathrm{V}(B)$. Data are shown as mean percent of baseline rate \pm SEM of 9-17 measurements per dosing group. The 0.5 - to 4-hr and 24-hr experiments were carried out separately. For a frame of reference, mean baseline beat rates were $211(0.5-4 \mathrm{hr})$ and $242(24 \mathrm{hr}) \mathrm{bpm}$ for Zn experiments and 198 and 216 bpm, respectively, for V experiments. There were no time-related changes related to control medium or the $6.25-\mu \mathrm{M}$ concentration of either metal. ${ }^{*} p<0.05 ;{ }^{* *} p<0.0001$.
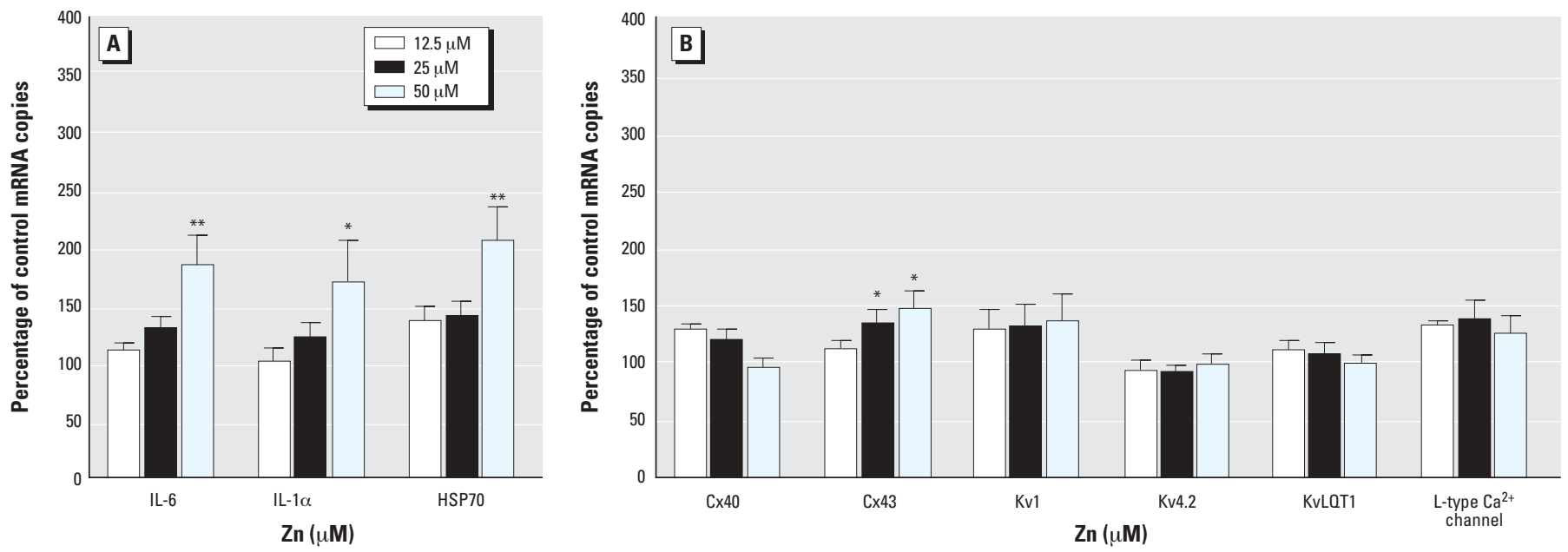

Figure 3. Changes in cardiac mRNA expression of $(A)$ inflammatory and stress markers and $(B)$ ion channel proteins after 6 -hr exposure to $12.5,25$, or $50 \mu M$ Zn. Exposure to $6.25 \mu \mathrm{M} Z \mathrm{n}$ had no effect on any transcript. Values are mean \pm SEM of three to four experiments, each comprising two to four independent measurements. ${ }^{*} p<0.05 ;{ }^{* *} p<0.0001$.
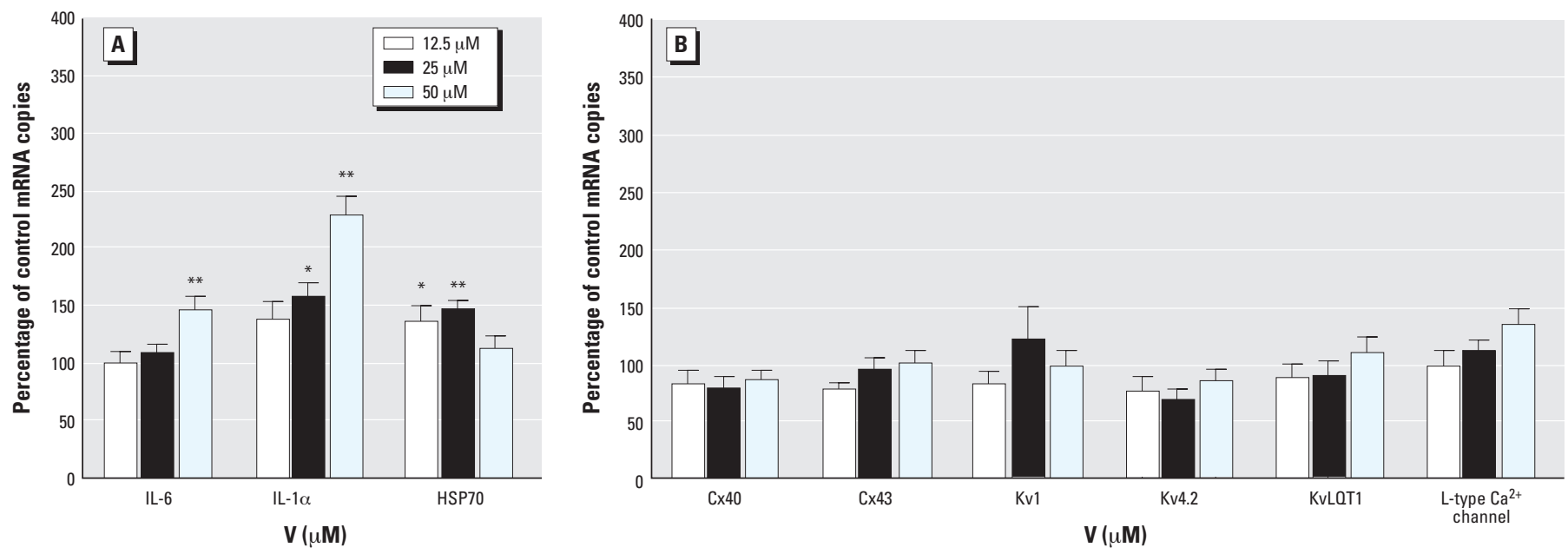

Figure 4. Changes in cardiac mRNA expression of $(A)$ inflammatory and stress markers and $(B)$ ion channel proteins after 6 -hr exposure to $12.5,25$, or $50 \mu \mathrm{M}$ V. Exposure to $6.25 \mu \mathrm{MV}$ had no effect on any transcript. Values are mean \pm SEM of three to four experiments, each comprising two to four independent measurements. ${ }^{*} p<0.05 ; * * 0.0001$. 
selecting representative genes encoding for several ionic currents responsible for maintaining cellular transmembrane electrochemical potential. A thorough review of these currents can be found in several references (Nerbonne 2000; Nerbonne et al. 2001; Strauss and Brown 2001).

In the heart, potassium and calcium currents are principal determinants of the time course of repolarization of cardiac myocytes; thus, their activity is responsible for the duration of the action potential plateau. After depolarization (a rapid rise in membrane potential primarily attributed to a rapid inflow of sodium ions), voltage-gated potassium channels open, allowing potassium to leave the cell. Simultaneously, calcium channels open to allow calcium ions to enter the cell. The combined and opposing effects of the potassium and calcium currents contribute

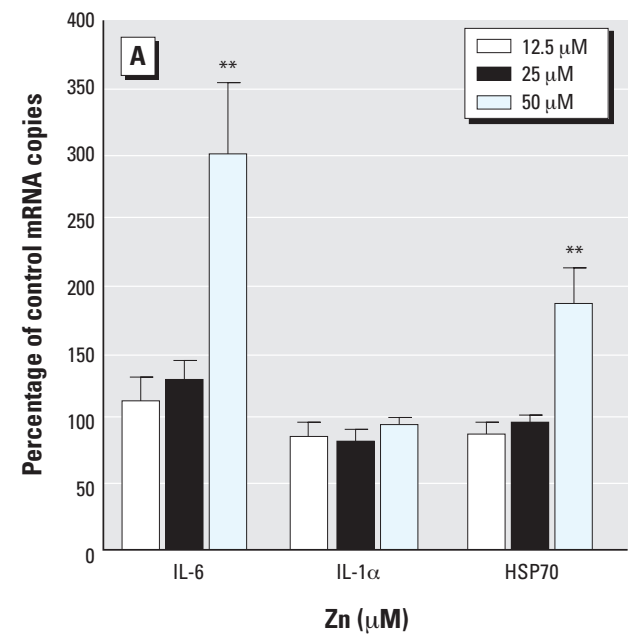

to repolarization (i.e., a return of the cell to its negative resting level) and provide the characteristic plateau seen in phase 2 of the cardiac cell action potential. Hence, alterations in gene expression of cardiac potassium and calcium channels may dramatically affect the capability of a cardiac myocyte to repolarize.

The effects of potassium channel gene regulation on ion currents, protein density, and the cardiac action potential have been demonstrated previously. Investigators crossing dominate negative Kv4.2 mice with Kv1.4 knockout mice essentially eliminated two important outward potassium currents, which produced an increase in action potential duration resulting in QT prolongation and arrhythmia (Guo et al. 2000). In streptozocin-induced diabetic rats, ventricular Kv4.2 mRNA levels were decreased 41\%, whereas Kv1.4 mRNA levels were increased $179 \%$ compared with nondiabetic controls. Western blot analysis showed a correlation between corresponding changes in the mRNA levels to decreases in $\mathrm{Kv} 4.2$ protein and increases in Kv1.4 protein (Nishiyama et al. 2001). A link between expression of potassium channel genes and postmyocardial infarction-related arrhythmias has been demonstrated, highlighting the importance of downregulated ion channels after cardiac injury (Huang et al. 2000). Increases in action potential duration and decreases in two potassium currents correlated to decreases in messenger and protein levels of Kv4.2/4.3 and Kv2.1. Nerbonne et al. (2001) provide a comprehensive summary of studies describing the consequences of genetic manipulation of cardiac potassium channels and the resulting effects on ion currents and cellular phenotype.

Figure 5. Changes in cardiac mRNA expression of $(A)$ inflammatory and stress markers and $(B)$ ion channel proteins after 24-hr exposure to $12.5,25$, or $50 \mu M \mathrm{Zn}$. Exposure to $6.25 \mu \mathrm{M} \mathrm{Zn} \mathrm{had} \mathrm{no} \mathrm{effect} \mathrm{on} \mathrm{any} \mathrm{transcript.} \mathrm{Values} \mathrm{are} \mathrm{mean} \pm$ SEM of three to four experiments, each comprising two to four independent measurements. ${ }^{*} p<0.05 ;{ }^{* *} p<0.0001$.
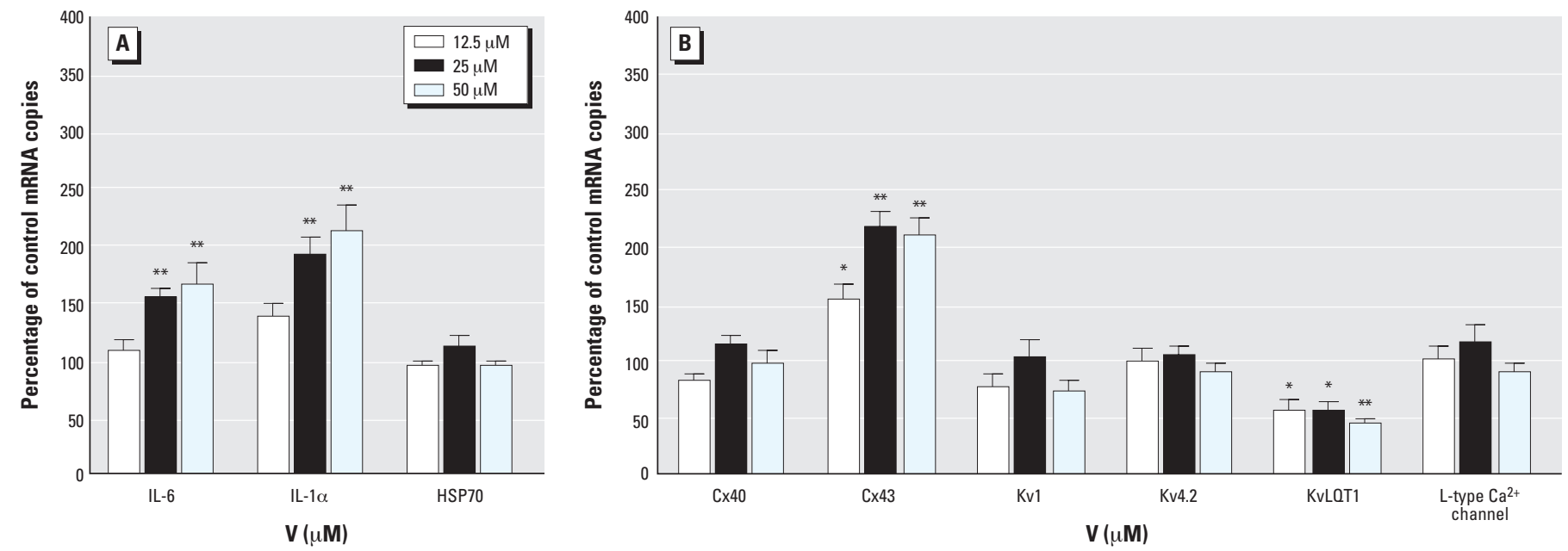

Figure 6. Changes in cardiac mRNA expression of $(A)$ inflammatory and stress markers and $(B)$ ion channel proteins after 24-hr exposure to $12.5,25$, or $50 \mu \mathrm{M}$ V. Exposure to $6.25 \mu \mathrm{MV}$ had no effect on any transcript. Values are means \pm SEM of three to four experiments, each comprising two to four independent measurements. ${ }^{*} p<0.05 ;{ }^{* *} p<0.0001$. 
In addition to the role played by ion channels, cellular coupling of cardiac myocytes is also vital for a coordinated propagation of electrical and chemical impulses. Moreover, the strength of electrotonic interaction is primarily related to the magnitude of cellular coupling as determined by gap junctional conductance. Gap junctions are specialized membrane proteins that regulate the passage of small molecules, ions, and electrical current between neighboring cells. In adult ventricular myocytes, gap junctions are composed primarily of Cx43, whereas $\mathrm{Cx} 40$ is present in the ventricle early in cardiac development (Kwak et al. 1999). Therefore, alterations in the expression of these proteins may well modify both membrane potential and gap junctional conductance, leading to changes in heart rate (beat rate in our cell culture model) and arrhythmia.

In this study we considered several representative genes involved in modulating repolarization, several proteins that carry potassium and calcium currents, and two proteins essential for gap junctional communication. We found both time- and metal-dependent changes in the expression of several ion channels and Cx43. Increased Cx43 gene expression was observed after both 6- and 24-hr exposure. After 24-hr exposure, $\mathrm{Zn}$ also produced statistically significant changes in gene expression of Kv4.2 (a fast-activating and -inactivating potassium current), KvLQT1 (a very slowactivating and -inactivating potassium current), and the $\alpha_{1}$ subunit of the L-type $\mathrm{Ca}^{2+}$ channel. We also saw a large increase in Kv1 (a fast-activating and slow-inactivating potassium current), although this change was not statistically significant. In contrast, the effect of $\mathrm{V}$ exposure on these channels was strikingly different. $\mathrm{V}$ induced a small increase in $\mathrm{Cx} 43$ gene expression but did not induce the expression of any ion channel gene. The only ion channel gene affected by V, KvLQT1, was actually downregulated. These findings are consistent with previous studies and support the likelihood that $\mathrm{Zn}$ and $\mathrm{V}$ exert their effects via distinct mechanisms (Evangelou and Kalfakakou 1993; Werdan et al. 1980).

Our data also show that transition metals commonly found on air pollution particles can also stimulate the production of inflammatory cytokines in cultured cardiomyoctes. Although still distinct, the changes noted in these transcripts after $\mathrm{Zn}$ and $V$ exposure are more similar than those noted for the ion channel and gap junction proteins. After 6- and 24-hr exposure, both $\mathrm{Zn}$ and $\mathrm{V}$ induced small but significant increases in the expression of IL-1 $\alpha$ and IL-6 genes and in HSP70, a protein shown to possess a protective role in inflammation and ischemic disease, and which may well have a regulatory role in cytokine biosynthesis. Whereas other cell types may produce a greater cytokine response, these data are important in demonstrating that $\mathrm{Zn}$ and $\mathrm{V}$ are both capable of altering the gene expression of cytokines in ventricular myocytes. This is potentially significant because cytokines can contribute to pathways leading to myocardial infarction, and in turn, myocardial infarction can further lead to hypertrophy of the myocardium, resulting in heart failure and arrhythmia. In addition, various cytokines have previously been shown to alter potassium currents (Diem et al. 2001, 2003), gap junction connectivity (Chandross et al. 1996; Chanson et al. 2001), and cardiac contractility (Finkel et al. 1992). Although our studies do not fully support a conclusion that cytokine release results in modification of ion channel gene regulation, we see a substantial cytokine response before major changes in ion channel gene regulation is intriguing and deserves further investigation.

Although in vitro cell culture models are valuable in exploring mechanisms by which PM components affect cardiac dysfunction, this work does have limitations. In this study, we measured only changes in mRNA expression. Changes in mRNA accumulation typically but not always result in modified protein production (Nishiyama et al. 2001). If the mRNA alterations seen here are translated into changes in protein assembly, we would expect to see changes in impulse formation, the safety factor that protects against aberrant impulse propagation and conduction patterns in myocardial tissue, as well as a significant inflammatory response. Twentyfour-hour changes in beat rate may be reflective of the altered gene regulation of Cx43 and the ion channels we chose to study. However, as a vast number of proteins must interact harmoniously to contribute to the many repolarization currents, it would be presumptuous to imply that the changes in spontaneous beat rate observed in this study are due to the transcriptional changes in the few ion channels we have considered. Because of the large number of potassium channels found in the heart and because of the redundancy in the activity of these channels, it is difficult to determine the effect that the message up- or downregulation of a small number of channels would have on repolarization and subsequent impulse formation. Nevertheless, it is evident that remodeling of the ion channels is occurring to some degree, more so during $\mathrm{Zn}$ exposure, and it is logical to assume that the transcription of ion channels other than those we have measured are likely to be affected as well.

In summary, this study provides intriguing data suggesting that the chemical composition of PM is very important in producing cardiac toxicity. Our data demonstrate that $\mathrm{Zn}$ and $\mathrm{V}$, metals commonly found in air pollution particles, have very distinct effects on the spontaneous beat rate of cultured cardiac myocytes, a measure that corresponds to heart rate in vivo. Although we cannot provide a temporal account for rapid changes in spontaneous beat rate, we do provide evidence that both metals, after a longer exposure, result in alterations in ion channel and $\mathrm{Cx}$ gene expression that would be expected to produce altered action potential characteristics and beat rate. Additionally, $\mathrm{Zn}$ and $\mathrm{V}$ also produce changes in the transcription of cytokines, which in previous studies have been linked to alterations in ion currents and gap junction connectivity. Furthermore, although we cannot exclude the influence of other biological processes, we provide stimulating hypothesis-generating evidence of a potential cellular mechanism explaining the acute changes in heart rate observed in epidemiologic and toxicologic studies of PM exposure. Further studies are being conducted to determine the effects of $\mathrm{Zn}, \mathrm{V}$, and other PM constituents on the cardiac action potential, the phosphorylation state of the connexins and functional measures of cellular coupling after both short-term and long-term exposures. These studies will help determine the precise mechanisms by which these metals exert their distinct effects on the heart.

\section{References}

Calderon-Garciduenas L, Gambling TM, Acuna H, Garcia R, Osnaya N, Monroy S, et al. Canines as sentinel species for assessing chronic exposures to air pollutants: part 2. Cardiac Pathol Toxicol Sci 61:356-367.

Campen MJ, Nolan JP, Schladweiler MC, Kodavanti UP, Costa DL, Watkinson WP. 2002. Cardiac and thermoregulatory effects of instilled particulate matter-associated transition metals in healthy and cardiopulmonary-compromised rats. J Toxicol Environ Health A 65:1615-1631.

Carter JD, Ghio AJ, Samet JM, Devlin RB. 1997. Cytokine production by human airway epithelial cells after exposure to an air pollution particle is metal-dependent. Toxicol Appl Pharmacol 146:180-188.

Chandross KJ, Spray DC, Cohen RI, Kumar NM, Kremer M, Dermietzel R, et al. 1996. TNF alpha inhibits Schwann cell proliferation, connexin46 expression, and gap junctional communication. Mol Cell Neurosci 7:479-500.

Chanson M, Berclaz PY, Scerri I, Dudez T, WernkeDollries K, Pizurki L, et al. 2001. Regulation of gap 
junctional communication by a pro-inflammatory cytokine in cystic fibrosis transmembrane conductance regulator-expressing but not cystic fibrosis airway cells. Am J Pathol 158:1775-1784.

Diem R, Hobom M, Grotsch P, Kramer B, Bahr M. 2003. Interleukin-1 beta protects neurons via the interleukin-1 (IL-1) receptor-mediated Akt pathway and by IL-1 receptor-independent decrease of transmembrane currents in vivo. Mol Cell Neurosci 22:487-500.

Diem R, Meyer R, Weishaupt JH, Bahr M. 2001. Reduction of potassium currents and phosphatidylinositol 3-kinase-dependent AKT phosphorylation by tumor necrosis factor-(alpha) rescues axotomized retinal ganglion cells from retrograde cell death in vivo. J Neurosci 21:2058-2066

Evangelou A, Kalfakakou V. 1993. Electrocardiographic alterations induced by zinc ions on isolated guinea pig heart preparations. Biol Trace Elem Res 36:203-208.

Finkel MS, Oddis CV, Jacob TD, Watkins SC, Hattler BG, Simmons RL. 1992. Negative inotropic effects of cytokines on the heart mediated by nitric oxide. Science 257:387-389.

Frampton MW. 2001. Systemic and cardiovascular effects of airway injury and inflammation: ultrafine particle exposure in humans. Environ Health Perspect 109(suppl 4):529-532.

Guo W, Li H, London B, Nerbonne JM. 2000. Functional consequences of elimination of $i(t o, f)$ and i(to,s): early afterdepolarizations, atrioventricular block, and ventricular arrhythmias in mice lacking Kv1.4 and expressing a dominantnegative Kv4 alpha subunit. Circ Res 87:73-79.

Huang B, Qin D, El-Sherif N. 2000. Early down-regulation of $\mathrm{K}^{+}$channel genes and currents in the postinfarction heart. J Cardiovasc Electrophysiol 11:1252-1261.

Kalfakakou VP, Evangelou AM, Benveniste J, Arnoux B. 1993. The effects of $\mathrm{Zn}^{2+}$ on guinea pig isolated heart preparations. Biol Trace Elem Res 38:289-299.
Kodavanti UP, Moyer CF, Ledbetter AD, Schladweiler MC, Costa DL, Hauser R, et al. 2003. Inhaled environmental combustion particles cause myocardial injury in the Wistar Kyoto rat. Toxicol Sci 71:237-245.

Kwak BR, van Kempen MJ, Theveniau-Ruissy M, Gros DB, Jongsma HJ. 1999. Connexin expression in cultured neonatal rat myocytes reflects the pattern of the intact ventricle. Cardiovasc Res 44:370-380.

Leicht M, Briest W, Holzl A, Zimmer HG. 2001. Serum depletion induces cell loss of rat cardiac fibroblasts and increased expression of extracellular matrix proteins in surviving cells. Cardiovasc Res 52:429-437.

Liao D, Creason J, Shy C, Williams R, Watts R Zweidinger R. 1999. Daily variation of particulate air pollution and poor cardiac autonomic control in the elderly. Environ Health Perspect 107:521-525.

Nemmar A, Hoet PHM, Vanquickenborne B, Dinsdale D, Thomeer M, Hoylaerts MF, et al. 2002. Passage of inhaled particles into the blood circulation in humans. Circulation 105:411-414.

Nerbonne JM. 2000. Molecular basis of functional voltage-gated $\mathrm{K}^{+}$channel diversity in the mammalian myocardium. J Physiol 525 Pt 2:285-298.

Nerbonne JM, Nichols CG, Schwarz TL, Escande D. 2001. Genetic manipulation of cardiac $\mathrm{K}(+)$ channel function in mice: what have we learned, and where do we go from here? Circ Res 89:944-956.

NIH. 1996. Guide for the Care and Use of Laboratory Animals. NIH Publ No. 85-23. Bethesda, MD:National Institutes of Health.

Nishiyama A, Ishii DN, Backx PH, Pulford BE, Birks BR, Tamkun MM. 2001. Altered $\mathrm{K}^{+}$channel gene expression in diabetic rat ventricle: isoform switching between Kv4.2 and Kv1.4. Am J Physio (Heart Circ Physiol) 281:H1800-H1807.

NRDC. 1996. Breath-taking: Premature Mortality Due to Particulate Air Pollution in 239 American Cities. Washington, DC:National Resources Defense Council.
Pekkanen J, Peters A, Hoek G, Tiittanen P, Brunekreef B, de Hartog J, et al. 2002. Particulate air pollution and risk of ST-segment depression during repeated submaximal exercise tests among subjects with coronary heart disease: the Exposure and Risk Assessment for Fine and Ultrafine Particles in Ambient Air (ULTRA) study. Circulation 106:933-938.

Peters A, Dockery D, Muller J, Mittleman M. 2001. Increased particulate air pollution and the triggering of myocardial infarction. Circulation 103:2810-2815.

Peters A, Liu E, Verrier RL, Schwartz J, Gold D, Mittleman M, et al. 2000. Air pollution and incidence of cardiac arrhythmia. Epidemiology 11:11-17.

Pope CA III, Verrier RL, Lovett EG, Larson AC, Raizenne ME, Kanner RE, et al. 1999. Heart rate variability associated with particulate air pollution. Am Heart J 138:890-899.

Ross R. 1999. Atherosclerosis: an inflammatory disease. N Engl J Med 340:115-126.

Strauss H, Brown A. 2001. Molecular diversity and distribution of cardiac ion channels. In: Foundations of Cardiac Arrhythmias: Basic Concepts and Clinical Approaches (Spooner P, Rosen M, eds). New York:Marcel Dekker, 121-149.

U.S. EPA (U.S. Environmental Protection Agency). 1996. National Ambient Air Quality Standards for Particulate Matter; Proposed Rule. Fed Reg 61:65638-65671.

Werdan K, Bauriedel G, Bozsik M, Krawietz W, Erdmann E. 1980. Effects of vanadate in cultured rat heart muscle cells. Vanadate transport, intracellular binding and vanadate-induced changes in beating and in active cation flux. Biochim Biophys Acta 597:364-383.

Wichers LP, Nolan JP, Winsett DW, Ledbetter AD, Kodavanti UP, Schladweiler MCJ, et al. In Press. Effects of instilled combustion-derived particles in spontaneously hypertensive rats. Part I. Cardiovascular responses. Inhal Toxicol. 